\title{
The Malaise of Globalization in East Asia: Income Inequality, Perceived State Capacity, and Anti-Establishment Attitudes
}

\author{
Mark Weatherall, Min-Hua Huang, and Taehee Whang
}

\begin{abstract}
This paper examines how inequality produced by globalization undermines the confidence of citizens that the government can resolve their problems, incubating growing anti-establishment sentiment. Applying the latest data from Asian Barometer Survey (ABS), the authors found that anti-establishment attitudes can be best explained by citizens' perceptions of a lack of state capacity and the state's persistently weak political performance. Analysis using multilevel modeling suggests that income inequality and weak economic growth further aggravate anti-establishment tendencies. This phenomenon, however, is most apparent in the countries of East Asia. Countries in Southeast Asia are generally less affected because they continue to enjoy rapid economic growth due to latecomer advantage in the global economy.
\end{abstract}

Key Words: globalization, inequality, perceived state capacity, anti-establishment

$\mathrm{I}^{\mathrm{n}}$ n his 2005 bestseller, The World Is Flat: A Brief History of the Twenty-First Century, New York Times columnist Thomas L. Friedman made a compelling case for globalization, arguing that the development of web technologies was creating a level playing field for commerce, enabling developing societies to effectively compete with established economies in the West for the first time. Since the 1990s, global inequality has indeed declined - a comprehensive study under the auspices of the World Bank estimated that the global Gini Index in

*Mark Weatherall(markweatherall@ntu.edu.tw) is a Postdoctoral Fellow of the Center for East Asia Democratic Studies at National Taiwan University, Taipei, Taiwan.

**Min-Hua Huang(neds5103@gmail.com) is Associate Professor at the Department of Political Science and the Director of the Center for East Asia Democratic Studies at National Taiwan University, Taipei, Taiwan.

***Taehee Whang(thwhang@yonsei.ac.kr) is Professor at the Department of Political Science and International Studies, Seoul, South Korea.

This work was supported by the Ministry of Education of the Republic of Korea and the National Research Foundation of Korea(NRF-2016S1A3A2925085). 
2008 was around 70.5, representing a decline of approximately 2 Gini points. Furthermore, the main "winners" over the two decades from 1988 to 2008 were countries who were at around the median of the global income distribution in 1988. In terms of population, these rapidly growing middle income countries were overwhelmingly dominated by Asian countries (Laker and Milanovic 2013). In China, impressive economic growth has lifted hundreds of millions of people out of poverty since the 1990 s and narrowed the gap with the advanced economies of the West. Developing economies in Southeast Asia have also experienced two decades of impressive economic growth. In the same period, only the advanced economies in the region, most notably Japan, have seen their incomes stagnate.

On the surface, East Asia appears to be the global economic success story of the last two decades, achieving impressive economic growth at the same time as lifting hundreds of millions of people out of poverty and closing the gap with the advanced economies of the West. Even after the global economic crisis of 2007-2008 that seriously impacted many countries in the region, East Asia has retained its status as the main driver of global economic growth. However, behind the economic success of East Asia hides a more sobering development - increasing income inequality within countries, with the poorest sections of society unable to keep up with new national elites who were the main beneficiaries of rapid economic growth. Furthermore, growing inequality has led to increased polarization between the haves and have-nots, a phenomenon which has been linked to rising social activism across the region. In particular, in economies that enjoyed rapid growth together with declining inequality during the 1960 s and 1970 - in particular South Korea, Taiwan, and Hong Kong growing inequality has led to increasing dissatisfaction with regime performance and rising civil activism against the government.

This paper examines how inequality produced by globalization undermines the confidence of citizens that the government can resolve their problems, incubating growing anti-establishment sentiment. ${ }^{1}$ In the past, Western scholars have viewed East Asia as the winners of globalization. In this view, the region has largely escaped the malaise of globalization, such as the relocation of jobs

\footnotetext{
${ }^{1}$ In this paper, we define "anti-establishment" as an attitudinal orientation that is deeply distrustful of traditional political elites and professional politicians. People who hold anti-establishment views prefer populist candidates who have never held public office or are perceived as a political outsiders, such as Donald Trump in United States or Rodrigo Duterte in the Philippines. Although these populist politicians may in fact be members of political or economic elites themselves, they are able to effectively portray themselves as outsiders in order to appeal to growing anti-establishment sentiment within society.
} 
and worsening polarization of income distribution. However, like elsewhere in the world, the rising costs of capital, intensifying market competition, major changes in the industrial structure, and large influxes of migrants have led to growing concentrations of wealth in the hands of the few and the hollowing out of the middle class. These problems are frequently experienced by ordinary people in their everyday lives. The rise of political activism in East Asia, particularly in Taiwan and Hong Kong, where anti-China sentiments have been a significant factor in protest movements, in fact reflect the negative effects of globalization in the two societies. As the world's second largest economy and its largest trading market and manufacturing base, China has had a major impact on its neighboring economies, particularly smaller ones such as Hong Kong or Taiwan. In addition, as economic globalization has eroded national borders, smaller economies are subject to its influence and feel extremely vulnerable. The more developed economies in East Asia, in particular Taiwan, Hong Kong, South Korea, Japan, and Singapore, have been particularly affected by China's rise. The Southeast Asian countries, while relatively less impacted by the rise of China, also feel the change China brought to their economy during the process of globalization, but in a less dramatic way. These countries are still in the stage of rapid economic development, and continue to enjoy late-developer advantages because of their cheaper labor costs. If we can systematically analyze how the economic inequality resulting from globalization influences the political dynamics in different countries, this can also help us understand the reasons behind the rise of anti-establishment movements that have emerged across the world, as well as helping governments identify solutions to these antiestablishment sentiments.

The paper is organized as follows. The first section examines how globalization is driving worsening inequality. The second section looks at the political implications of the rise of inequality, focusing on anti-establishment movements. The third section develops our research hypotheses, exploring the relationship between individual level attitudes and anti-establishment attitudes. The fourth section is the research design. The fifth section is the empirical findings. The sixth session discusses the implications of the findings. The final section is the conclusion.

\section{INEQUALITY AND GLOBALIZATION}

Although proponents of globalization have argued that globalization has enabled developing countries to "catch up" with the West and reduced global inequality, 
there is significant empirical evidence to suggest that globalization has worsened inequality within countries. For example, the International Monetary Fund (2007) found that with the exception of Sub-Saharan Africa and the former Soviet states, inequality within countries has risen across the world, including in the advanced industrialized economies, as well as the emerging economies of Eastern Europe, Latin America, and Asia. Figure 1 presents the changes in the ratio of the incomes of the top 10\% compared to remaining $90 \%$ of citizens averaged over five year intervals in 11 Asian countries. ${ }^{2}$ We measure inequality by comparing the income of the top 10\% of citizens to the remaining 90\% of citizens instead using traditional measures that compare the incomes of the top $10 \%$ or $20 \%$ to the bottom $10 \%$ or $20 \%$ because we intend to tap into the so-called "hollowing out" of the middle class, whereby the only winners are the very richest in society. ${ }^{3}$ Our data cover a thirty-year period, from the genesis of globalization in the 1980 s to the rapid escalation of globalization over the last decade in the context of rapid advances in communications technologies. The data show that this period of rapid globalization has had different effects on patterns of inequality across the region. First, in the region's advanced economies (in particular Japan, South Korea, Singapore, and Taiwan), the age of globalization has coincided with sharp increases in inequality. Second, rapid growth also led to sharp increases in inequality in China through the 1980 os and the 1990s, as the more prosperous coastal regions gained most of the economic benefits from the country's rapid growth while poorer internal regions where left behind (Chen and Fleisher 1996). However, over the last decade income inequality in China has actually fallen slightly as both interregional and intraregional inequality has declined (Fan and Sun 2013). Third, Southeast Asian countries have either seen falls in the level of inequality (in the case of Malaysia and Thailand), or only modest increases (in the case of Vietnam and the Philippines).

\footnotetext{
${ }^{2}$ The income data is derived from two sources: The World Wealth and Income Database (China, Japan, Korea, Taiwan, and Singapore) and World Development Indicators (Cambodia, Malaysia, Mongolia, Philippines, Thailand, and Vietnam). The World Wealth and Income Database, available at http://www.wid.world/; World Bank World Development Indicators, available at http://data. worldbank.org/data-catalog/world-development-indicators

${ }^{3}$ The "hollowing out" of the middle class has been widely observed in industrialized economies across the world. For example, Acemoglu and Autor (2011) argue that the middle class is being hollowed out with the mechanization of many middle skill jobs. In addition, Blanchard and Willmann (2016) argue that freer trade is "crowding out" traditional middle class occupations. As the middle class is "hollowed out," the benefits of economic growth are increasingly disproportionately shared by the very richest in society.
} 
Figure 1. Ratio of the Average Income in East Asia, Top $10 \%$ vs. Bottom $90 \%$

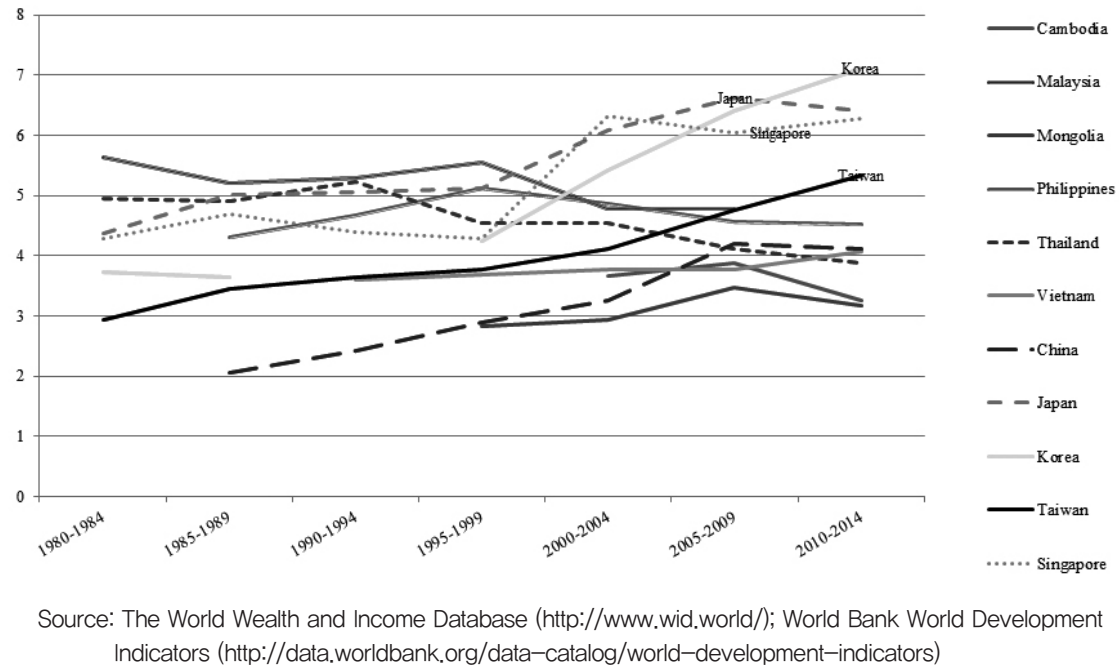

Figure 1 shows that at the start of the period, the emerging economies of Thailand and Malaysia had the worse levels of income inequality in the region, perhaps reflecting the persistence of traditional class-based cleavages and agricultural modes of production. However, by the end of the period, inequality in the region's developed economies (South Korea, Japan, Singapore, and Taiwan) far exceeded the rest of the region. How much can these changes can be explained by the effects of globalization? In Table 1, we look at the correlation between each country's level of globalization, measured using the KOF Globalization Index ${ }^{4}$ and the levels of inequality as reported in Figure 1. For comparison, we also include three Western countries - the United States, the United Kingdom, and Germany - which have also faced the challenge of rising inequality in recent decades. Our figures show that for the countries in East Asia that have witnessed the most rapid increases in inequality - Japan, South Korea, and Singapore (Taiwan and Hong Kong are excluded due to a lack of data) ${ }^{5}-$

4 The KOF index of Globalization is composed of three globalization indices: economic, social, and political. Since the highlight of this paper is about economic inequality, we only adopt economic globalization as our measure. The KOF index of Globalization is available at http://globalization.kof. ethz.ch/

5 Although we lack longitudinal data, we can estimate the current level of economic globalization for Hong Kong and Taiwan based on the findings of recent studies. First, research has found that 
the growth in inequality is strongly associated with increased exposure to of globalization. We also find a significant positive association between exposure to globalization and growing inequality in China, as well as in the United States, the United Kingdom, and Germany. However, we do not find a significant positive association in Mongolia or any of the Southeast Asian countries, with the exception of Singapore. In fact, in Malaysia and Thailand, greater exposure to globalization has a statistically significant negative association with income inequality.

Table 1. Correlation of Globalization and Income Inequality Since 1980

\begin{tabular}{cc}
\hline Country & Correlation \\
Korea & $.905^{* *}$ \\
France & $.893^{* *}$ \\
Japan & $.875^{* *}$ \\
United States & $.856^{* *}$ \\
United Kingdom & $.855^{* *}$ \\
Germany & $.779^{* *}$ \\
Singapore & $.744^{* *}$ \\
Vietnam & $.643^{* *}$ \\
Mongolia & .585 \\
Philippines & .486 \\
Cambodia & .320 \\
Malaysia & -.534 \\
Thailand & $-.800^{* *}$
\end{tabular}

Note: ${ }^{*} \mathrm{p} \leqq 0.05,{ }^{* *} \mathrm{p} \leqq 0.01$. Entry is Pearson Correlation.

Source: KOF index of Globalization (http://globalization.kof.ethz.ch/); Income Inequality has two sources of data, one is the World Wealth and Income Database (http://www.wid.world/) and the other is World Bank World Development Indicators (http://data,worldbank.org/data-catalog/world-development-indicators).

This finding shows that exposure to globalization does not necessarily produce greater income inequality. Two factors might be at work here. First, for industrialized countries, globalization is more likely to produce greater income

Hong Kong's level of economic globalization is about the same level as Singapore's (Ernst \& Young 2012). Therefore, we apply Singapore's figure to estimate Hong Kong's level of economic globalization. Second, Taiwan ranks $35^{\text {th }}$ on the A.T. Kearney/Foreign Policy (KFP) Globalization Ranking. We took the average scores of KOF economic globalization for the countries ranked with \pm 5 places of Taiwan as the Taiwan's estimate. 
inequality due to a "hollowing out" of the middle class and a relocation of jobs overseas to countries with lower labor costs. However, for emerging countries, the trend may work in the opposite direction, as the class cleavages of traditional society break down and rural residents have new opportunities to migrate to cities to fill the jobs that have migrated from the advanced countries. Free trade can weaken the middle class in industrialized countries at the same time as it expands the middle class in developing countries (Blanchard and Willmann 2016). Second, competition from a rising China is also likely to worsen the effect of globalization on growing inequality. In particular, two of China's neighbors, Japan and South Korea, have a very strong positive association between globalization and inequality. Although we lack data on exposure to globalization in Hong Kong and Taiwan, we can reasonably infer that given their increasing economic dependence on the Chinese economy, the two cases also show a strong association between exposure to globalization and inequality. ${ }^{6}$

\section{PERCEIVED STATE CAPACITY AND RISE OF ANTI-ESTABLISHMENT MOVEMENTS}

Across the world, rising income inequality and the failure of mainstream politicians to provide a cure have increased the attractiveness of antiestablishment alternatives. Inequality has also been blamed for rising populist sentiment, such as the growing resonance of anti-immigrant messages (Bloemraad 2016). Furthermore, citizens who are frustrated by the failure of politicians to solve these problems seem to be abandoning mainstream politicians in their droves. In 2016, Brexit and the election of Donald Trump as U.S. President were widely attributed to growing inequality and anxiety among the middle class (Goodwin 2016; Reeves 2016). Across Europe, politicians running on an explicitly anti-establishment message, from Marie Le-Pen in France to Viktor Orbán in Hungary have been gaining traction. Although Rodrigo Duterte swept to power on a populist platform in the Philippines, the populist wave has not yet had the same dramatic effect in Asia. However, antiestablishment sentiment in the region appears to be growing as traditional

\footnotetext{
${ }^{6}$ Taiwan's cultural ties and close geographical proximity to China facilitated the outflow of Taiwanese manufacturing industry to China. The jobs that replaced the lost manufacturing jobs were generally less secure and less well paid, worsening the island's income inequality (Meer and Adams 2006). In Hong Kong, worsening inequality has been blamed on the influx of migrants from mainland China and economic restructuring after the 1980 s as Hong Kong manufacturers relocated their operations to the Pearl River delta area (Hong Kong Half-Yearly Economic Report 2012).
} 
politicians grapple with the challenges of globalization and rising inequality. Populist or "outsider" politicians such as Lee Jae-myung in South Korea and Ko Wen-je in Taiwan have benefited from rising distrust toward traditional politicians. ${ }^{7}$

However, although inequality has been widely blamed for the rise of antiestablishment sentiment, there has been very little scholarly work done in this area. Most of the work done on the consequences of inequality for political behavior have focused on its effects on political participation. For example, Brady (2003) argues that while greater inequality to may increase the motivation of poor people to engage in politics, it decreases their ability to do so. In addition, Dahl (2006) argues that inequality depresses political engagement, particularly among the poor. Solt (2008) also finds that economic inequality has a strong negative effect on political interest, participation in politics, and electoral engagement among all sections of society with the exception of the wealthiest. These studies all assume that growing inequality will reduce political efficacy and political interest, causing people to disengage from politics.

In recent years, however, although inequality has caused increasing frustration with mainstream politics, rather than abandoning political participation altogether, people have instead switched their support to anti-establishment alternatives. Why might we be witnessing a switch to anti-establishment alternatives in response to growing inequality rather than a complete withdrawal from politics? One explanation is that with the rise of the Internet and social media, there are now more non-institutional channels available for political participation. In particular, populist politicians have effectively leveraged the Internet and social media to communicate their message and organize politically (Bartlett, Birdwell, and Littler 2011). With the rise of the Internet and social media, it is now much easier for populist politicians and parties to bypass traditional institutional channels (such as the traditional media and established political parties) and connect directly with disillusioned voters, providing an alternative to the binary choice of voting for establishment politicians or withdrawing from politics altogether.

In this study, rather than measuring political participation, we instead test whether globalization has coincided with a growth in anti-establishment beliefs. We measure anti-establishment beliefs using the following item from

${ }^{7}$ Lee Jae-myung, currently mayor of Seongnam City and a potential future presidential candidate, has promised to eliminate Korea's "establishment cartel" and has been compared to both Donald Trump and Bernie Sanders (Kim 2016). Former physician Ko Wen-je defeated the Kuomintang (KMT) in its traditional Taipei City stronghold partly by appealing to his status as a political outsider (Ramzy 2014). 
the Asian Barometer Survey: "You can generally trust the people who run our government to do what is right." We choose this item because it does not specify a specific regime, and so can hopefully capture citizens' distrust in the political establishment or system as a whole, rather than in individual politicians or parties. Next, we are interested in the relationship between the perceived failure of politicians to address the problem of inequality and the anti-establishment beliefs of citizens. In order to test whether citizens believe that politicians have failed to address the problem of inequality, we measure the number of respondents who both believe that the income distribution in their own country is unfair and that addressing income inequality is the responsibility of the government.

Figure 2 shows that there is a strong association between anti-establishment beliefs among citizens and a perceived failure of politicians to resolve inequality. ${ }^{8}$ In other words, a perceived failure of governments to ensure a fair distribution of income appears to be a major driver of anti-establishment sentiment. Generally speaking, citizens in East Asia are less satisfied with their government's performance on reducing income inequality and more likely to distrust those in power than their counterparts in Southeast Asia. In particular, economies that are the most reliant on China (Taiwan and Hong Kong and to a lesser extent South Korea) have the highest levels of anti-establishment sentiment and very high levels of dissatisfaction with their government's performance on reducing income inequality. This finding suggests that economic dependence on China further undermines the ability of the government to resolve income inequality, contributing to growing anti-establishment sentiment. Only two countries - Myanmar and Mongolia - are clear outliers, combining high levels of dissatisfaction with performance on reducing income inequality with relatively low levels of anti-establishment beliefs, suggesting that in these countries, frustration about the perceived unfairness of income distribution has not yet become a significant source of anti-establishment sentiment.

\footnotetext{
${ }^{8}$ The correlation between the anti-establishment attitude and perceived failure of politicians to resolve inequality is 0.158 , significant at the $\mathrm{p}<=0.001$ level. If we exclude the two ostensible outliers in Figure 2, Myanmar and Mongolia, the correlation increases to 0.215 ( $\mathrm{p}<-0.001)$. This shows the two variables are closely related, but not conflated since the two measures are conceptually distinct and only show a moderate correlation. For the latter regression analysis, the correlations between attitudinal independent variables and anti-establishment attitude range between -0.011 and 0.393, suggesting that they are related but distinct.
} 
Figure 2. Anti-establishment Sentiment and Dissatisfaction with Income Inequality

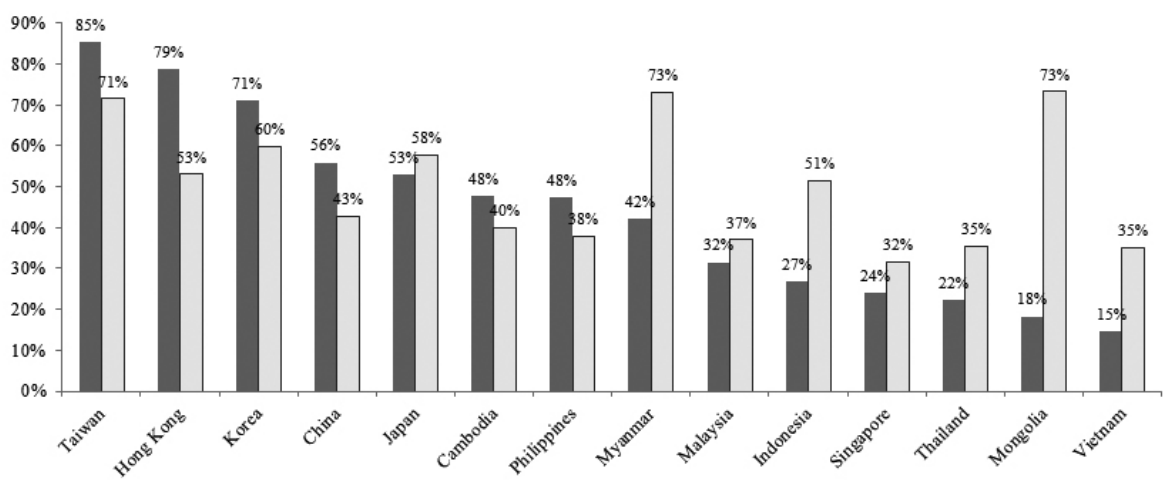

- Not Trust Those Who Rule

口Unfair Income Distribution \& G ovemment Responsibility to Reduce Inequality

Source: ABS 4

\section{HYPOTHESES}

The worsening distribution of income under globalization is one of the most serious challenges for governance performance. This is because this worsening income distribution does not only affect the very poor, it has also had a major impact on the middle classes (Acemoglu and Autor 2011; Blanchard and Willmann 2016). In fact, the concentration of wealth arising from globalization has benefited only a very small section of society. Increases in wages can no longer keep up with wealth accumulation through rising real estate prices and increased stock value. Indeed, once inflation is taken into account, in many countries, income levels have barely risen at all. ${ }^{9}$ This has meant that salaried workers, including both white collar and managerial workers, are finding that their incomes cannot keep up with the very wealthy who derive their incomes from non-wage sources, and income distribution is becoming increasingly polarized. In addition, this polarization is reflected in the growing gap between

${ }^{9}$ For instance, between 2000 and 2011, Taiwan saw virtually no growth in real wages (Dou and Hsu 2011). Although wages for higher earners have increased in Singapore, low earners not have seen their wages rise (Chuan 2016). 
the very wealth and the majority of people who rely on employment as their primary income source, rather than the gap between the people at the very top and those at the very bottom. In other words, we are witnessing a hollowing out of the middle class.

The main effect of the hollowing out of the middle class, which was previously a source of social stability, is that dissatisfaction is not only directed at the incumbent regime, but also at the entire political class. Because politicians of all stripes have been unable to provide any solutions to the problems, people have started blaming the entire system. This anti-establishment sentiment is expressed in a widespread belief that politicians are only concerned about the interests of a small elite rather than benefiting ordinary people. Increasing numbers of people complain that political elites have dominated for too long, and have lost the ability to respond to popular demands. The failure of these politicians to respond to popular demands has led to a collapse of confidence in the system. ${ }^{10}$

Based on the discussion above, anti-establishment sentiment in the countries that have suffered from worsening inequality resulting from globalization can be explained by three different factors: (1) Government performance, meaning citizens' views on the long-term performance of the government; (2) Perceived state capacity, meaning how citizens perceived the state's capacity to solve problems; (3) Social and psychological factors, meaning collective psychological factors that produce cognitive mobilization among citizens against political elites. These three factors have one point in common: when views of the existing system or political elites are more negative, anti-establishment tendencies are stronger. Furthermore, these anti-establishment sentiments provide a strong incentive for political participation

For each of the three factors proposed above, we select two related but conceptually distinct measures from the Fourth Wave of the ABS. In terms of government performance, we measure citizens' evaluations of how democracy functions in their country. This measure reflects evaluations of the overall performance of the system, rather than that of a specific party in a specific period of time. In addition, although this item mentions "democracy," it can be applied to both democratic and nondemocratic regimes, since regardless of the level of democracy as assessed by experts, citizens across Asia generally believe that their country is democratic. Another important related factor is citizens'

${ }^{10}$ Scholars have long distinguished between instrumental and intrinsic regime support. Here, we assume support for the regime is instrumental and contingent on its satisfactory performance. For the distinction between instrumental and intrinsic regime support, see Bratton and Mattes (2001). 
perceptions of the level of corruption in the government. Since impressions of corruption are built up over a long period, these sentiments also reflect longterm assessments of regime performance. Therefore, this study uses these two indicators as explanatory factors measuring system performance. The hypotheses are as follows:

Hypothesis 1: The greater citizens' dissatisfaction with the functioning of democratic institutions, the higher the level of antiestablishment tendencies.

Hypothesis 2: The greater citizens' perceptions of corruption, the higher the level of anti-establishment tendencies.

Perceived state capacity can be measured by whether citizens believe the regime can solve long-term problems. ${ }^{11}$ The negative effects of globalization have made citizens increasingly impatient and cynical about whether the government is able to solve their problems. We expect that this phenomenon will produce increased anti-establishment views. Another indicator of state capacity is whether the government can respond to the needs of the people. This item captures whether the state has both the capacity and the willingness to respond to people's problems. A perceived lack of responsiveness is also expected to increase anti-establishment views.

Hypothesis 3: The greater the belief among citizens that the existing system can resolve citizens' problems, the greater the level of antiestablishment tendencies.

Hypothesis 4: The more that citizens perceive that the government does not respond to the needs of citizens, the greater the level of antiestablishment tendencies.

In terms of social and psychological factors, the change in political attitudes among the middle class from widespread support for the establishment to growing anti-establishment views is produced by a process of cognitive mobilization. Therefore, a higher level of psychological involvement is more likely to produce a change in attitudes (Dalton 1984). At the same time, this anti-

\footnotetext{
${ }^{11}$ There is a large literature on state capacity which focuses on the ability of the state to implement official goals (Geddes 2004; Hanson and Sigman 2013). In this study, however, we are interested in how citizens subjectively perceive state capacity. Therefore, we select two items from the ABS measuring citizens' perceptions of state capacity.
} 
establishment sentiment reflects a widespread belief that the government should be held directly accountable for worsening income distribution. When citizens believe that the government has failed to address growing income inequality, they are more likely to hold anti-establishment attitudes.

Hypothesis 5: The higher the level of psychological involvement in politics, the greater the level of anti-establishment tendencies.

Hypothesis 6: The more that citizens perceive that income distribution is unequal and the government should take responsibility, the greater the level of anti-establishment tendencies.

Finally, we consider the relationship between education level and antiestablishment tendencies. The growing unequal distribution of income in the recent wave of globalization has also hit the better educated middle classes hard. Therefore, we expect that in countries suffering from worsening inequality under the wave of globalization, level of education is positively correlated with antiestablishment tendencies.

Hypothesis 7: The greater citizens' level of education, the higher the level of anti-establishment tendencies.

\section{RESEARCH DESIGN}

This study tries to answer three important questions. First, it tries to explain the causes of anti-establishment tendencies in East Asia. Second, it looks at macro factors at the national level, to see whether there are differences in the factor model for explaining anti-establishment tendencies in societies that have been influenced by globalization to different levels. Third, we provide a systematic expiation of the interactive effect of different macro- and individual-level factors. Conceptually, our dependent variable is anti-establishment tendencies. The most obvious sign of this wave of anti-establishment sentiment is the increasing antiestablishment mood found in many countries, with citizens preferring figures from outside the political establishment and with no record of serving in public office, showing their lack of trust in traditional politicians. Therefore, we select the item measuring whether respondents agree that "You can generally trust the people who run our government to do what is right" from the Fourth Wave of the ABS. For this item, we carry out ordinal logistic regression using the original 
four ordinal response categories (strongly disagree, disagree, agree, strongly agree). In terms of the multilevel analysis (hierarchical nonlinear modeling), due to the complexity of using a large number of ordinal categories, we instead use binary coding depending on whether the respondent agreed or disagreed.

For the individual-level explanatory variables, we select the corresponding variables as outlined in the hypotheses presented in the preceding section, and also adding gender and age as control variables. The variables for each of the seven hypotheses are as follows: (1) On the whole, how satisfied or dissatisfied are you with the way democracy works in the country? (negative coding i.e. level of dissatisfaction); (2) How widespread do you think corruption and bribe-taking are in the national government? (positive coding i.e. level of corruption); (3) Over the long run, our system of government is capable of solving the problems our country faces? (negative coding i.e. incapable of solving problems); (4) How well do you think the government responds to what people want? (negative coding i.e. does not respond to what people want); (5a) How interested would you say you are in politics? (5b) How often do you follow news about politics and government? (5c) When you get together with your family members or friends, how often do you discuss political matters? (positive coding i.e. level of psychological involvement); (6a) How fair do you think income distribution is in the country? (6b) It is the responsibility of the government to reduce the differences between people with high income and those with low incomes? (negative coding for fairness of income distribution, positive coding for responsibility of government for fair income distribution); (7) Level of education (positive coding, from lowest to highest). For psychological involvement, we take the average value following the re-coding operation, while fairness of income distribution and responsibility of government for fair income distribution are coded as binary variables, with respondents who believe income distribution is unfair and that it is the responsibility of government for fair income distribution coded as 1 , and others coded as 0 .

In terms of analytical strategy, we first carry out regression analysis for each country using individual-level data to test the hypotheses in each of the countries. We mentioned in Section 2 that countries have been affected by globalization at different levels. We expect that in the countries or regions that have been affected the most by globalization, including as Japan, South Korea, Taiwan, Hong Kong, and Singapore, the effects are stronger. However, this expectation can only be verified using multilevel modeling. Therefore, after testing the hypothesis in each country, we include macro-level factors on globalization in the model, to systematically test their contextual effects, and their crossover effects when combined with individual level factors. These 
interactions between the two levels can explain the reasons for the emergence of anti-establishment tendencies in Asia.

For country-level variables, we select five important explanatory factors which measure the "level of economic inequality," "level of economic globalization," "economic growth rate," "level of national development," and "level of democracy" in each country. using the following measures: R10\%/B90\% Income ratio (The World Wealth and Income Dataset and World Development Indicator), index of economic globalization (KOF index of Globalization), GDP per capita growth, PPP (World Development Indicator), natural logarithm value of GDP per capita, PPP (World Development Indicator), and reverse freedom house score (Freedom House). Since the ABS database covers 14 countries and territories, for the multilevel analysis, we analyze the country-level variables for each country separately to observe the regression coefficient result for the macro-level factors and individual-level factors, carrying out a systematic analysis of the effects of individual-level factors, the contextual effects of the macro-level factors, and the crossover effects of the macro-and individual-level factors together. We center individual-level explanatory variables by using the country means, except for binary variables (which are fixed), and center macrolevel variables by using the grand means of the available countries in analysis. ${ }^{12}$

\section{EMPIRICAL FINDINGS}

Table 2 presents the results of the ordinal logistic regression for the 14 countries or territories in the Fourth Wave of the ABS. The most significant finding is that of statistically significant relationship in 13 of the 14 countries and territories (with the exception of Hong Kong). This finding is also generally consistent regardless of contextual factors, suggesting the strong relationship between the belief that the regime is unable to resolve problems and anti-establishment tendencies. Another factor related to perceived lack of state capacity, the government's lack of responsiveness, is also strongly associated with antiestablishment tendencies, corroborating Hypothesis 4 in 11 out of the 14 countries and territories. These results show that a lack of state capacity is one of the main reasons behind anti-establishment tendencies.

${ }^{12}$ In the next section, we report the result of hierarchical nonlinear modeling based on 13 countries except Vietnam, where data of perceived corruption is unavailable. We did, however, also include the Vietnamese dataset by excluding the variable of perceived corruption, and found no substantial difference. Therefore, we report the full model specification (with perceived corruption variable) without Vietnamese data. 
Table 2. Regression on "Not Trust Those Who Govern"

\begin{tabular}{|c|c|c|c|c|c|c|c|c|c|c|c|c|c|c|c|}
\hline Predictors & JP & KR & TW & HK & SG & $\mathrm{CN}$ & VN & MN & $\mathrm{PH}$ & TH & MA & IN & KH & MY & Sig. \\
\hline \multicolumn{16}{|l|}{ Government Performance } \\
\hline Dissatisfaction of Democracy & + & + & + & + & + & + & + & & + & & + & & + & + & $11 / 14$ \\
\hline Perceived Corruption & + & + & + & + & & & $x$ & & + & + & + & + & + & + & $10 / 13$ \\
\hline \multicolumn{16}{|l|}{ Perceived State Capacity } \\
\hline $\begin{array}{l}\text { System Can't Solve } \\
\text { Long-term Problems }\end{array}$ & + & + & + & & + & + & + & + & + & + & + & + & + & + & $13 / 14$ \\
\hline Govt. Fails to Response & + & + & + & + & + & + & + & & + & & + & & + & + & $11 / 14$ \\
\hline \multicolumn{16}{|l|}{ Social Psychological Factors } \\
\hline Psychological Involvement & + & & + & & & & - & - & - & - & & - & & & $7 / 14$ \\
\hline $\begin{array}{l}\text { Govt. Held Responsible } \\
\text { for Inequality }\end{array}$ & + & + & + & & & + & + & - & & & & & + & & $7 / 14$ \\
\hline \multicolumn{16}{|l|}{ Background Controls } \\
\hline Education & & & + & & & + & & & + & + & + & & + & & $6 / 14$ \\
\hline Age & & & & & & - & & - & + & & & & & & $3 / 14$ \\
\hline Male & + & & & & & - & & & & & & & & & $1 / 14$ \\
\hline
\end{tabular}

Source: ABS 4

Note: Entry is the sign of unstandardized coefficient by the level of significance $p \leqq 0.05$.

The next group of explanatory variables, government's long-term performance, while slightly less powerful, is also very significant in explaining the antiestablishment tendencies. First, dissatisfaction with democracy was significantly associated with anti-establishment tendencies in 11 of the 14 countries and territories (Hypothesis 1). Second, perception of corruption was significantly associated with anti-establishment tendencies in 10 of the 13 countries (data unavailable in Vietnam) and territories (Hypothesis 2). The explanatory power of the two hypothesis is on a par with Hypothesis 4, showing that negative impressions of the government's long-term performance are also an important factor predicting the rise of anti-establishment forces. Therefore, the above four hypotheses were supported, meaning that these hypotheses are found to be statistically significant regardless of the national context, indicating a high degree of reliability.

Next are the social and psychological factors. The factors produced significant findings in 7 out of the 14 countries and territories. First, political interest (Hypothesis 5) produced a significant negative outcome in five countries (all of them in Southeast Asia), and a positive relationship in only Japan and Taiwan, showing that the relationship is strongly influenced by contextual factors. With regard to blaming the government for the failure to resolve income inequality, although a positive relationship was only found in 6 of the countries (Hypothesis 
6), these cases were concentrated in countries with a high level of correlation between globalization and income distribution - including Japan, South Korea, Taiwan, China, and Vietnam, showing that the explanatory power of this factor is also closely related to contextual factors. Whether these two findings can pass the significance test when the country-level variable is considered requires further tests in hierarchical nonlinear modeling reported later in this section.

For the control variables, a high level of education has significant effect in 6 of the 14 countries and territories. However, in contrast to our expectations in Hypothesis 7, with the exceptions of China and Taiwan, we did not find this result in countries and territories with a high correlation between globalization and inequality. This result shows that Hypothesis 7 has limited explanatory power. As for age and gender, we found significant effects only in a small number of cases.

The above results show that we need a comprehensive analysis of how contextual factors affect the explanatory power of each of the hypotheses. For this purpose, we carry out hierarchical nonlinear modeling, setting crossover effects for the individual level variables corresponding to the seven hypotheses. We are concerned with finding out: (1) Whether the individual-level effects show significant effects regardless of the context; (2) Whether the national macro-level factors directly affect the level of anti-establishment tendencies; (3) Whether the explanatory power of individual-level variables are affected by the interaction with national macro-level effects? Table 3 presents the results of hierarchical nonlinear modeling.

As shown in Table 3, for the individual-level findings, we find that Hypothesis 1 to Hypothesis 4 (the four indicators for weak government performance and lack of state capacity) show a consistent positive effect regardless of countrylevel factors. This result confirms the findings of the regression analysis in Table 2. In other words, anti-establishment tendencies are primarily associated with citizens' long-term negative evaluations of government performance and a belief that the government lacks the ability to resolve problems. It is worth noting that when we test for crossover effects, only the positive relationship between the government's lack of responsiveness and anti-establishment tendencies is weakened when income inequality is reduced. This shows that only Hypothesis 4 is subject to contextual factors that require careful interpretation. The major implication of this finding is that when the government has successfully reduced income inequality, perceived lack of responsiveness is no longer an important factor generating anti-establishment tendencies, which indicates that people are affected more by an improved reality than sheer perception. In terms of level of education, the explanatory power is on the borderline of statistical significance under different contexts, showing that a higher level of education 
produces stronger anti-establishment tendencies. This finding is consistent with Hypothesis 7, meaning that main driver of anti-establishment tendencies is actually relatively privileged sections of society rather than traditionally marginalized groups.

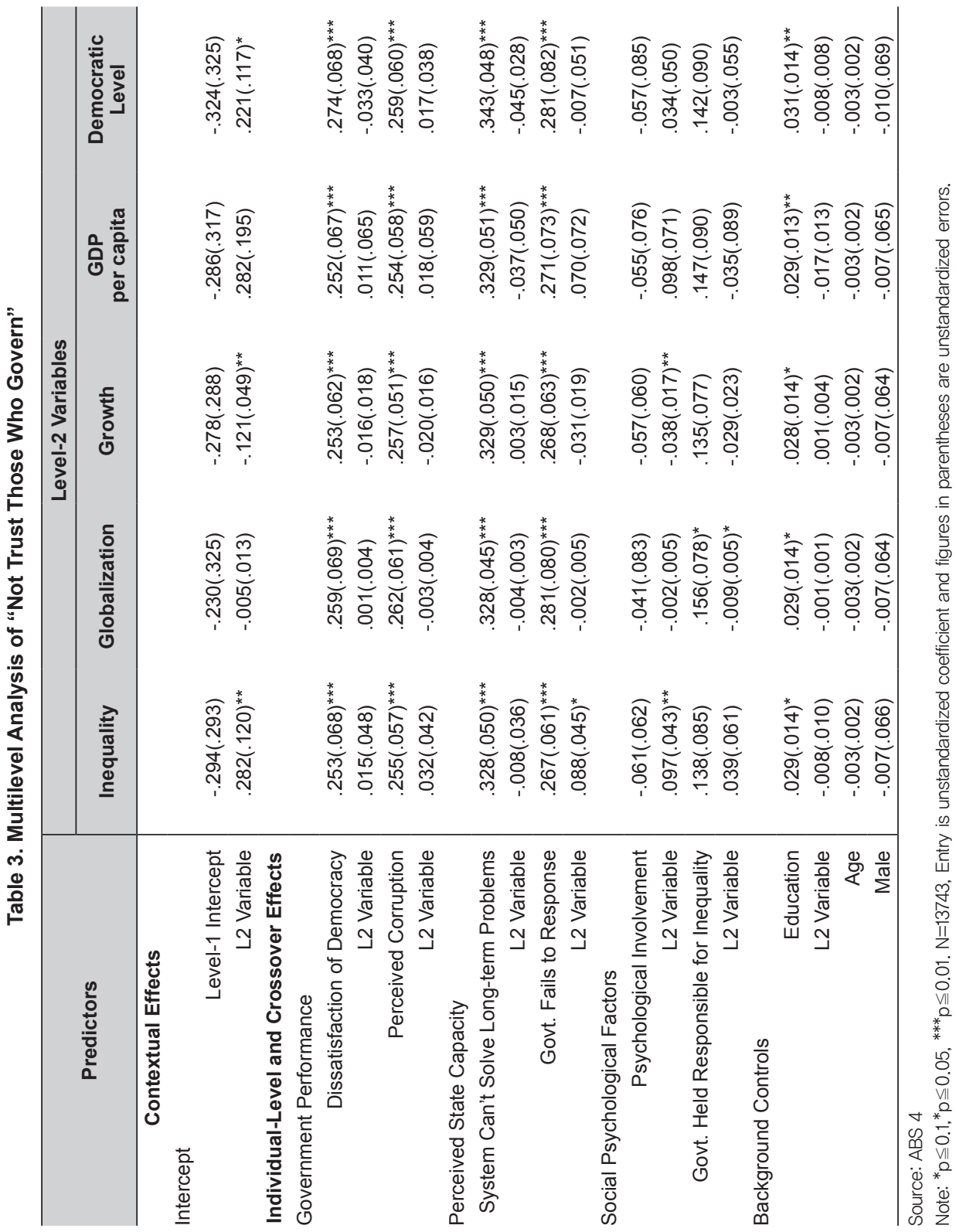


As to contextual effects, when we set the model reference values to the baseline profile (individual-level variables are set to country-means except fixing binary variables at zero ${ }^{13}$ and country-level variables are set to grand means with specification of random errors), we find three significant results of macro variables on the individual-level intercept terms. First, income inequality is positively associated with anti-establishment tendencies, suggesting that greater inequality is associated with stronger anti-establishment attitudes. Likewise, when the level of inequality is significantly lower than the grand means, the level of anti-establishment tendencies also falls. Second, economic growth rate is inversely related to anti-establishment tendencies. The better the economy, the less the negative sentiment towards the political establishment. Finally, greater level of democracy is positively associated with anti-establishment tendencies, but only vary marginally at the significance level $p<0.1$. This suggests that people in democracies tend to show stronger anti-establishment tendencies than their counterparts in authoritarian countries. These three findings demonstrate that the key factors influencing the rise and fall of anti-establishment tendencies are the real economic problems countries have faced as a result of globalization. As long as a country can reduce its inequality problem or increase its level of economic growth, it can reduce the anti-establishment sentiment in the society.

Finally, we examine crossover effects. Our main findings here are for the social and psychological factors in Hypothesis 5 and Hypothesis 6. As shown in Table 3, for the psychological involvement variable, lower economic growth and greater inequality both strengthen the relationship between psychological involvement and anti-establishment sentiment. For instance, when income inequality is high or economic growth is low, psychological involvement has a positive relationship with anti-establishment tendencies. However, when growth is high and inequality is low, psychological involvement has a negative relationship with anti-establishment tendencies. This signals two different groups of people who show strong anti-establishment attitudes: those who are indifferent to politics when the economy is good and those who are very concerned about politics when the economy is bad. The former are likely to be socioeconomically underprivileged, while the latter are likely to be socioeconomically privileged. There is one more significant crossover effect found under the specification of macro variable Globalization: the positive individual-level relationship between those who hold the government responsible for income inequality and

13 When doing so, the two binary variables mean "Government Does Not Held Responsible for Inequality", and "Female". 
the anti-establishment tendencies can be ameliorated when the country has a greater level of economic globalization. This finding shows that citizens are aware of the government's predicament if a country is faced with a significant impact of globalization, and therefore may be more forgiving. However, this crossover effect is very marginal in magnitude, and does not remove the original positive relationship between holding the government responsible and antiestablishment effects. ${ }^{14}$ In other words, most citizens are concerned about whether their problems are resolved, and empathy with the government's predicament cannot eliminate anti-establishment tendencies.

\section{DISCUSSION}

The advantage of hierarchical nonlinear modeling is that it enables analysts to assess how a macro-level contextual variable systematically explain an individual-level dependent variable through direct or indirect causal paths with precise decomposition of variance. However, to derive a full picture of their effects, it is very useful to present the marginal and joint effects of a single macro-level and single individual-level predictor to unravel how contextual, crossover, and individual-level effects are intertwined. By doing this, we can show the predicted composite effect of the variables at each level on the dependent variable. In this section, we present two previously reported findings with consideration for the empirical range of variation for the macroand individual-level variables. The first is the income inequality ratio and level of psychological involvement; and the second is economic growth rate and perceived lack of state capacity.

For the first case, as Table 3 shows, when the ratio of income inequality changes in a country, it not only affects the level-1 intercept, it also changes the level-1 beta coefficients for other explanatory variables specified with crossover effects. Therefore, when we apply the baseline profile ${ }^{15}$ to analyze how the

${ }^{14}$ Longitudinal data on the KOF index of economic globalization is available for 12 ABS surveyed countries (Taiwan and Hong Kong are exceptions). For the past decade (2006-2015), the average change of economic globalization is 0.9 with a standard deviation 6.5. This means that most of the Asia-Pacific countries have a relatively stable level of economic globalization, except for Mongolia $(+14.7)$ and Vietnam (+9.4). Considering the relative small magnitude of the crossover effect (-0.009) to the individual-level beta (0.156) at the baseline profile, the actual influence is quite limited given the stable level of economic globalization.

${ }^{15}$ The baseline profile below is set at a male respondent who thought income distribution unfair and believed the government should be held responsible, with attributes held at the country average (average dissatisfaction of democracy, average perceived level of corruption, average level of per- 
macro- and micro-level predictors influence the predicted probability of the dependent variable, we need to calculate the composite result of the odds-ratio before adding the contribution from the targeted macro- and micro- predictors. Then, we can start moving the macro- or micro- variables from the values they were centered (or fixed) to the maximum and minimum and calculate the corresponding predicted probability. In this way, we can understand the actual range of possible empirical variations of the of the macro and micro predictors.

As Table 4 shows, we vary the level of income inequality and psychological involvement within the empirical range (3 to 7.5 times of income difference and from not at all to very much politically interested) and calculate the predicted probability of showing anti-establishment tendencies by holding all other variables at the baseline level (all at the country average level except setting a male respondent who thought income distribution unfair and the government should be held responsible). The marginal increase of the predicted probability for anti-establishment attitudes by level of psychological involvement from the lowest to highest are between $-15 \%$ (40\% to $25 \%$ ) and $+13 \%$ (60\% to $73 \%$ ), depending on the contextual ratio of income inequality: with a higher level of income inequality, the marginal increase by psychological involvement turns from negative to positive variation. Similarly, the marginal increase of the predicted probability for anti-establishment attitudes by level of contextual income inequality from low to high is between $20 \%$ (40\% to 60\%) and $48 \%$ (25\% to $73 \%$ ): the stronger the level of psychological involvement, the greater range of impact for income inequality. The change of the variation direction in terms of psychological involvement and the augmented variation range caused by income inequality both show how the positive crossover effects influence the predicted probability of anti-establishment attitudes. Notice when we control at any level of psychological involvement, the series of predicted probability by income inequality shows an upward trend, reflecting the contextual effect of income inequality. On the other hand, when controlling income inequality at the middle level (4.5 to 6.5), the variation of predicted probability based on the lowest to highest level of psychological involvement is limited (within $\pm 7 \%$ ), showing why the individual-level effects of psychological involvement are not significant. For the combination of non-significant individual-level effect and significant crossover effect, the significant variation will be only substantiated at the close to end level (minimum or maximum) of the conditional variable. 
Table 4. Probability of Answering "Not Trust Those Who Govern" by Inequality and Psychological Involvement

\begin{tabular}{c|ccccccc}
\hline \multirow{2}{*}{$\begin{array}{c}\text { R10/B90 } \\
\text { Ratio }\end{array}$} & \multicolumn{7}{|c|}{ Level of Psychological Involvement } \\
\cline { 2 - 7 } & $\mathbf{1}$ (not at all) & $\mathbf{1 . 5}$ & $\mathbf{2}$ & $\mathbf{2 . 5}$ & $\mathbf{3}$ & $\mathbf{3 . 5}$ & $\mathbf{4}$ (very much) \\
\hline 3 & $40 \%$ & $37 \%$ & $35 \%$ & $32 \%$ & $29 \%$ & $27 \%$ & $25 \%$ \\
3.5 & $42 \%$ & $40 \%$ & $38 \%$ & $35 \%$ & $33 \%$ & $31 \%$ & $29 \%$ \\
4 & $44 \%$ & $43 \%$ & $41 \%$ & $39 \%$ & $37 \%$ & $36 \%$ & $34 \%$ \\
4.5 & $47 \%$ & $45 \%$ & $44 \%$ & $43 \%$ & $42 \%$ & $41 \%$ & $40 \%$ \\
5 & $49 \%$ & $48 \%$ & $48 \%$ & $47 \%$ & $46 \%$ & $46 \%$ & $45 \%$ \\
5.5 & $51 \%$ & $51 \%$ & $51 \%$ & $51 \%$ & $51 \%$ & $51 \%$ & $51 \%$ \\
6 & $53 \%$ & $54 \%$ & $54 \%$ & $55 \%$ & $56 \%$ & $56 \%$ & $57 \%$ \\
6.5 & $55 \%$ & $57 \%$ & $58 \%$ & $59 \%$ & $60 \%$ & $61 \%$ & $62 \%$ \\
7 & $58 \%$ & $59 \%$ & $61 \%$ & $63 \%$ & $64 \%$ & $66 \%$ & $68 \%$ \\
7.5 & $60 \%$ & $62 \%$ & $64 \%$ & $66 \%$ & $69 \%$ & $71 \%$ & $73 \%$ \\
\hline
\end{tabular}

Note: Predicted probabilities are evaluated with at the baseline profile except the macro variable Inequality and the micro variable Psychological Involvement.

Table 5 shows another example by varying economic growth rate (macro variable) and level of perceived lack of state capacity (micro variable) by holding other variables at the baseline profile. As can be seen, the marginal change of the level of perceived lack of state capacity varies from $+24 \%$ to $+18 \%$, and most of the time the variation range is stable between $22 \%$ and $24 \%$. This indicates a positive individual-level effect of perceived lack of state capacity without crossover effects from the macro variable of economic growth: at all levels of economic growth rates, the stronger the perceived lack of state capacity, the greater the anti-establishment attitudes. On the other hand, when controlling at one level of perceived lack of state capacity, the marginal change of predicted probability due to economic growth from lowest to highest is between - $34 \%$ and $-38 \%$, signifying a stable range of variation. This indicates that economic growth can produce a contextual effect to reduce anti-establishment attitudes, but this effect does is conditioned by level of perceived lack of state capacity.

By illustrating the above two examples, we can easily interpret how the individual-level effects, contextual effects, and crossover effects produce composite effects in terms of the marginal variation of the predicted probability for the dependent variable. However, an important caveat is that the estimates of predicted probability are conditional on the setting of the baseline profile (even if this is simply changing from a male to female respondent, or younger to a senior respondent) given the nature of nonlinear probability effects on the 
binary dependent variable. We have to be aware exactly which baseline profile is applied and how this will change the probability evaluation.

Table 5. Probability of Answering "Not Trust Those Who Govern" by Growth and Perceived Lack of Capacity

\begin{tabular}{c|cccc}
\hline \multirow{2}{*}{ Economic Growth (\%) } & \multicolumn{4}{|c}{ Perceived Lack of State Capacity } \\
\cline { 2 - 5 } & $\begin{array}{c}\text { Strongly } \\
\text { Disagree }\end{array}$ & Disagree & Agree & Strongly Agree \\
\hline 2 & $48 \%$ & $56 \%$ & $63 \%$ & $70 \%$ \\
3 & $44 \%$ & $52 \%$ & $60 \%$ & $67 \%$ \\
4 & $40 \%$ & $48 \%$ & $56 \%$ & $64 \%$ \\
5 & $37 \%$ & $44 \%$ & $53 \%$ & $61 \%$ \\
6 & $33 \%$ & $41 \%$ & $49 \%$ & $57 \%$ \\
7 & $30 \%$ & $37 \%$ & $45 \%$ & $54 \%$ \\
8 & $27 \%$ & $34 \%$ & $42 \%$ & $50 \%$ \\
9 & $24 \%$ & $30 \%$ & $38 \%$ & $46 \%$ \\
10 & $21 \%$ & $27 \%$ & $35 \%$ & $43 \%$ \\
11 & $19 \%$ & $24 \%$ & $31 \%$ & $39 \%$ \\
12 & $16 \%$ & $22 \%$ & $28 \%$ & $36 \%$ \\
13 & $14 \%$ & $19 \%$ & $25 \%$ & $32 \%$ \\
\hline
\end{tabular}

Note: Predicted probabilities are evaluated with at the baseline profile except the macro variable Inequality and the micro variable Psychological Involvement.

\section{CONCLUSION}

In this paper, we use various approaches to explain how the rise of antiestablishment sentiment is linked to the worsening income inequality under globalization. In recent years, this phenomenon has become increasingly apparent, not just through rising political activism, but also in electoral triumphs for populist politicians. Although populist politicians in Asia have not yet made the dramatic breakthroughs they have enjoyed in the West, our research shows that Asia has not escaped the effects of growing income inequality and rising anti-establishment sentiment. This anti-establishment sentiment reflects increasing impatience at the failure of traditional politicians to solve the problems faced by countries in an increasingly globalized world.

However, voting out experienced political elites from political leadership will not automatically solve the problem, and the political pendulum might 
even swing back in favor of professional politicians once the public realize that inexperienced political outsiders might cause even greater damage. If that is the case, there will be a strong backlash against anti-establishment politicians, and the wave of populism might be just a short-term phenomenon. The success or failure of anti-establishment politicians in the West will be closely watched in Asia, where populist politicians have so far failed to get much of an electoral foothold. If the anti-establishment politicians in Western countries are successful, they we can expect more similar politicians to emerge in East Asia. If they fail, this might discourage Asian citizens from going down the same path.

The signs of growing frustration with the political establishment can already be found across East Asia. In South Korea, trust in the political establishment has been undermined by the massive scandal facing president Park Geun-hye. Although no significant populist movement has yet emerged in Japan, the result of our regression analysis indicates that country already has the conditions for a populist alternative to emerge. In Singapore, the upcoming challenge is even more salient with the pressure of power succession as the current prime minister Lee Hsien Loong's health problem continue to worsen. In Taiwan, there are signs that the traditional two-party system dominated by the Kuomintang and Democratic Progressive Party may be entering a period of transition, providing potential opportunities for political outsiders with populist messages.

However, the late developers in the region, concentrated in Southeast Asia, are still enjoying a period of rapid growth. This growing prosperity is the flip side of the coin of economic globalization, coinciding with stagnant growth and growing inequality in developing countries. As long as these countries can maintain good economic performance, anti-establishment sentiment may be constrained. However, even with strong economic growth, anti-establishment sentiment might increase if the government fails to ensure a fair distribution of income, as seen in China where the top $1 \%$ of the population already hold one-third of the country's wealth (Tiezzi 2016). In the future, China's inequality is likely to worsen due to the combination of a highly capitalist economy and strong state regulation, leading to potentially more serious anti-establishment sentiment in the future.

Our study shows that the best solution for the national leaders to cope with growing anti-establishment sentiments is to improve economic performance and effectively reduce inequality. However, achieving these aims will be increasingly challenging due to the weakening capacity of the state under globalization. Increasingly, effective action relies on the coordination and cooperation between sovereign states. However, leaders may also be motivated to withdraw from such cooperation for political reasons or because citizens are increasingly skeptical 
about transnational cooperation. President Trump's decision to quit the TransPacific Partnership (TPP) trade deal on his first day in the White House is a striking example of the political obstacles to transnational cooperation, demonstrating how difficult it is for sovereign states to cooperate effectively to respond to the challenges of globalization. Unless domestic or cross-national solutions to the malaise of globalization are found, anti-establishment sentiment is likely to worsen in the future, threating the stability of regimes across the region. Finally, the rise of anti-establishment sentiment in Asia and elsewhere is an important direction for future research, both because of its important theoretical implications for the study of topics such as political participation and political cleavages, and also for its important implications for real world politics. One limitation of this research is that we still lack precise instruments to measure "anti-establishment sentiment." Future research can further refine these instruments, providing us with a better understanding of why citizens in Asia and elsewhere are increasingly rejecting mainstream politics and politicians.

\section{REFERENCE}

Acemoglu, Daron, and David Autor. 2011. "Chapter 12 - Skills, Tasks and Technologies: Implications for Employment and Earnings." In Handbook of Labor Economics, edited by David Card and Orley Ashenfelter, 4, Part B:1043-1171. Elsevier. Accessed at http://www. sciencedirect.com/science/article/pii/So169721811024105 (October 3, 2017).

Bartlett, Jamie, Jonathan Birdwell, and Mark Littler. 2011. "The New Face of Digital Populism.” Accessed at https://www.demos.co.uk/files/Demos_ OSIPOP_Book-web_03.pdf?1320601634 (October 3, 2017).

Blanchard, Emily, and Gerald Willmann. 2016. "Trade, Education, and the Shrinking Middle Class.” Journal of International Economics 99, 263278.

Bloemraad, Irene. 2016. "Immigrants, Brexit, Trump and Inequality." The Berkeley Blog. Accessed at http://blogs.berkeley.edu/2016/06/24/ immigrants-brexit-trump-and-inequality/ (June 24, 2016).

Bratton, Michael, and Robert Mattes. 2001. "Support for Democracy in Africa: Intrinsic or Instrumental?” British Journal of Political Science 31(3), 447-474.

Chen, Jian, and Belton M. Fleisher. 1996. "Regional Income Inequality and 
Economic Growth in China." Journal of Comparative Economics 22(2), 141-164.

Chuan, Toh Yong. 2016. "Outsourcing has depressed wages of many lowwage workers: MP Zainal Sapari.” The Straits Times. Accessed at http://www.straitstimes.com/singapore/manpower/outsourcing-hasdepressed-wages-of-many-low-wage-workers-zainal-sapari (February 13, 2016).

Dalton, Russell J. 1984. "Cognitive Mobilization and Partisan Dealignment in Advanced Industrial Democracies.” The Journal of Politics 46(1), 264284.

Dou, Eva, and Jenny W. Hsu. 2012. "Solving Taiwan's Wage Stagnation Mystery." WSJ. Accessed at http://blogs.wsj.com/chinarealtime/2012/10/03/ solving-the-mystery-of-taiwans-wage-stagnation/ (October 3, 2012).

Ernst \& Young, 2012. "Hong Kong and Singapore - 1st and 3rd in EY's Globalization Index 2011.” Online Report. Accessed at http://www. ey.com/gl/en/newsroom/news-releases/hong-kong-and-singapore--1st-and-3rd-in-ernst-and-youngs-globalization-index-2011 (February 8 , 2012).

Fan, C. Cindy, and Mingjie Sun. 2008. "Regional Inequality in China, 19782006." Eurasian Geography and Economics 49(1), 1-18.

Friedman, Thomas L. 2005. The World Is Flat: A Brief History of the TwentyFirst Century, 1st edition. New York: Farrar, Straus and Giroux.

Goodwin, Matthew. 2016. "Inequality, Not Personalities Drove Britain to Brexit.” POLITICO. Accessed at http://www.politico.eu/article/ inequality-not-personalities-drove-britain-to-brexit/ (June 28, 2016).

Government of the Hong Kong Special Administrative Region. 2012. "HalfYearly Economic Report 2012.” Accessed at http://www.hkeconomy. gov.hk/en/pdf/er_12q2.pdf (December 27, 2016).

International Monetary Fund. 2007. "Globalization and Inequality." In IMF World Economic Outlook (WEO)- Globalization and Inequality. Accessed at https://www.imf.org/external/pubs/ft/weo/2007/02/ (December 30, 2016).

Kim, Sam. 2016."This Korean Populist Is Getting Compared to Bernie Sanders." Bloomberg.com. Accessed at https://www.bloomberg.com/ news/articles/2016-11-24/harnessing-trump-and-sanders-koreanpopulist-rises-in-polls (November 24, 2016).

Lakner, Christoph, and Branko Milanovic. 2013. "Global Income Distribution: From the Fall of the Berlin Wall to the Great Recession." World Bank Policy Research Working Paper No. 6719. Washington, DC: World 
Bank.

Meer, Craig, and Jonathan Adans. 2006. "Specter of Inequality Haunts Taiwan.” Far Eastern Economic Review, 169(10).

Ramzy, Austin. 2014. "Mayor's Race Could Alter Balance of Political Power in Taiwan." The New York Times. Accessed at https://www.nytimes. com/2014/11/28/world/asia/taipei-mayors-race-could-alter-balanceof-taiwans-political-power.html (November 27, 2014).

Reeves, Richard R. 2016. "Inequality Built the Trump Coalition, Even If He Won't Solve It |Brookings Institution.” Brookings. Accessed at https:// www.brookings.edu/blog/fixgov/2016/o9/26/inequality-built-thetrump-coalition-even-if-he-wont-solve-it/ (September 26, 2016).

Solt, Frederick. 2008. "Economic Inequality and Democratic Political Engagement." American Journal of Political Science 52(1), 48-60.

Tiezzi, Shannon. 2016. "Report: China's 1 Percent Owns 1/3 of Wealth." The Diplomat. Accessed at http://thediplomat.com/2016/01/report-chinas1-percent-owns-13-of-wealth/ (December 27, 2016).

World Bank. 2016. "World Development Indicators.” Accessed at http://data. worldbank.org/data-catalog/world-development-indicators (December 27, 2016).

. 2016. "World Wealth \& Income Database." Accessed at http://www. wid.world/ (December 27, 2016).

[Received Jan 18, 2017; Revised Jan 31, 2017; Accepted Feb 9, 2017] 
